\section{ARTES, PERENIDADE, NOVIDADE E MEMÓRIA SOB AUGUSTO ${ }^{1}$}

\author{
Paulo Martins* \\ Recebido em: 23/11/2020 \\ Aprovado em: 16/12/2020
}

\begin{abstract}
RESUMO: Este artigo opera a relação entre a arte plástica produzida, a partir do culto imperial de Otávio Augusto, e as tópicas da perenidade e da novidade observadas pela poesia augustana. Essa arte plástica, que era útil ao serviço de Augusto, opera imortalidade e memória do princeps. A poesia não só reverbera a poesia grega antiga e helenística como também é dependente daquela produzida pelos poetae noui. O novo estilo plástico, por sua vez, distancia-se da arte plástica republicana e aproxima-se daquela produzida na Grécia clássica e helenística. O trabalho também se ocupa da compreensão de como a imagem do poeta, agente de sua arte, interage com a figura imortal de Augusto, agente da imortalidade da urbs, de sua arquitetura e de seus lugares sagrados.
\end{abstract}

PALAVRAS-CHAVE: perenidade; novidade; simulacrum; poesia augustana; culto imperial.

\section{ARTS, PERENNLALITY, NOVELTY, AND MEMORY UNDER AUGUSTUS}

\begin{abstract}
This article deals with the relationship between the plastic art, produced from the imperial cult of Augustus, and the topica of the perenniality and the novelty which are observed by Augustan poetry. This plastic art, which is useful to the service of Augustus, copes with the immortality and the memory of the princeps. In the other hand, the poetry reverberates the Ancient and Hellenistic Greek poetry as well as is dependent on the poetry of poetae noui. The new plastic style, in turn, it is far away from the Republic plastic art and it is very close to the Classic and Hellenistic Greek plastic art. This paper also deals with the compression of as the poet's image, agent of his art, acquaint with immortal figure of Augustus, agent of immortality of urbs, architecture, and shrines.
\end{abstract}

KEYWORDS: perenniality; novelty; simulacrum; Augustan poetry; Imperial cult.

${ }^{1}$ Este trabalho foi apresentado parcialmente na conferência "Cultural Memory in Early Roman Empire” na Université Paris-Est Créteil em 2017 sob o título "A New Perspective on the post mortem image of Augustus".
*Professor Livredocente de língua e literatura latina, Universidade de São Paulo. Bolsista de produtividade em pesquisa, CNPq. paulomar@usp.br 


\section{NOVA ARTE AUGUSTANA}

$1 \begin{aligned} & \text { inda que os termos classicismo ou idealismo augustano, utilizados pela História da } \\ & \text { Arte Antiga, a fim de classificar as artes visuais da época de Augusto - em oposição } \\ & \text { ao "realismo" ou ao "verismo" republicano -, façam parte de uma taxonomia }\end{aligned}$ superada, que, diz muito mais sobre o lugar de fala do historiador da arte do que sobre o lugar dos romanos do século I AEC, ainda assim é inegável que a época de Augusto inaugura nas artes plásticas, pictóricas, arquitetônicas e literárias algo descontinuado em relação ao momento histórico anterior, configurando, pois, um novo padrão de produção artística para os romanos. Essa taxonomia, uma inadequação terminológica, deve-se, segundo Elsner, a um afastamento dos historiadores dos conceitos êmicos, entendidos como "conceptualizations of the material-cultural world which come from within antiquity itself and might have been recognizable by the ancients" ${ }^{2}$ e, constituindo-se como critérios éticos, que nada mais é do que observar a cultura antiga, no caso, com uma visada, própria aos nossos dias, reatualizando as imagens e os textos com os olhos do presente.

Uma boa forma de superar essa carência é recuperar a compreensão que os romanos tinham daquilo que viam na pedra ou no metal das esculturas e das gemas e a pintura sobre a superfície plana da tábua ou do estuque, observando como nomeavam essas experiências, como as significavam em palavras sem que isso pudesse dar conta de uma nomenclatura rígida e crua, típica da expertise de um connoisseur. Isto é, estamos diante das seguintes questões: qual nome os antigos davam aos diversos tipos de estátuas e pinturas? Qual vocabulário empreenderam para nominar técnicas dos artistas no processo de emulação ou a explicitação dos limites entre as representações? ${ }^{3} \mathrm{Ou}$ ainda, como as letras se apropriam das técnicas plástico-pictóricas em viés homológico? ${ }^{4}$

Parece-me que o "novo estilo augustano" ${ }^{5}$ traz em si os conceitos de excelência e do belo de sorte que, para esses romanos do século de Augusto, não se deve figurar alguém exatamente como é, já que ninguém é capaz de ter em si tudo que há melhor. Propércio, por exemplo, falando de Cynthia - uma construção poética fictícia - diz que sua beleza não era compatível com uma gestação - non, non humani partus sunt talia dona: ista decem menses non peperere bona - Tais dotes não, não são humanos/dez meses não seriam capazes de concebêlos. ${ }^{6}$ Assim entendendo Cynthia como uma construção artística, só se pode compreendê-la como o somatório de partes muito belas. Pois bem, o novo estilo da época de Augusto significa compreendê-lo não como operação de um único modelo, uma cópia exata de algo que existe, um decalque do modelo sobre a cera, um espelhamento, mas a constituição de um todo excelente a partir de partes perfeitas. Podemos dizer que a Cynthia de Propércio, ${ }^{7}$ assemelha-se

\footnotetext{
${ }^{2}$ Elsner (2014, p. 1-34). falante. Hor. Ars, 361-365.

${ }^{5}$ Zanker (1990, p. 79-100): “ New Imperial style”.

${ }^{6}$ Prop. 2.3.27-28.

${ }^{7}$ Martins (2017c, p.183-92).
}

${ }^{3}$ Plin. Nat., 34.9.17-19.93: estátuas de bronze; 35.1.1-59.202: pinturas; 36.1.1-70.204: estátuas de pedra. Cic., Or. 5; 9; Brut. 70-71; Inv. 2.1-4.; De Or. 3.25-27; Ver. 2.4.5; 4.12 etc. Quint., Inst. 2.13; 12.10.1-9 etc. ${ }^{4}$ Ver Plut. De glor. Ath. 3.346ss: Simônides de Céos chama à pintura poesia silenciosa e à poesia pintura 
à Helena de Zêuxis, comentada por Cícero no Sobre a Invenção e por Dionísio de Halicarnasso no Sobre a Imitação. ${ }^{8}$ Propércio diz: si quis vult fama tabulas anteire vetustas, hic dominam exemplo ponat in arte meam - Se alguém quer superar a fama de antigas pinturas/ tome nesta arte minha mulher como modelo". ${ }^{9}$ Dessa maneira, construir figurativamente alguém supõe, nessa chave, operar o gênero demonstrativo no qual a amplificação é fator imperioso. Mais do que isso, a reunião de partes perfeitas resultando o todo excelente é prática que tem fundamento na imagética divina, que consequentemente compreende aquilo a que os antigos propõem

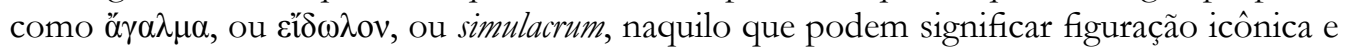
anicônica dos deuses dos quais imagens de modelos "reais" não há. ${ }^{10}$

A arte augustana então figura a nobreza, a nobilitas em largo senso, aristocratas, plebeus, equestres, reconhecidos ou afamados, de modo diferente ao que fez a arte da república, já que a primeira a forma do jovem, do novo e do vigor garante a excelência almejada pelos vitoriosos (figura 1) e a segunda a consolidação da austeridade, da experiência, da estirpe opera a chave do poder, do respeito e da honra (figura 2). Bom exemplo é comparar um retrato de Augusto com o de um nobre republicano:

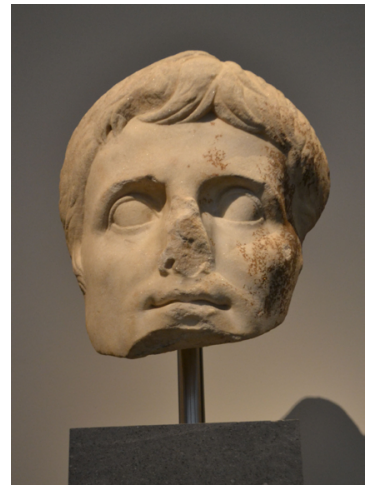

Figura 1 - Cabeça Colossal de Augusto, Metropolitan Museum, Nova York Inv. 21.88.94 $4^{11}$

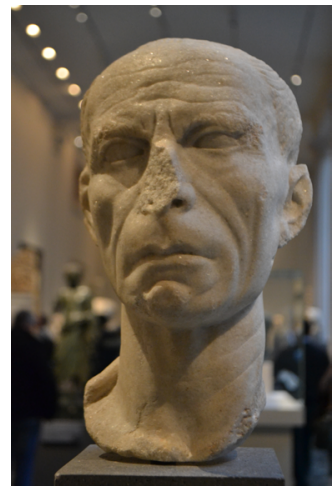

Figura 2 - Retrato de Homem, meados EC -14-30 do séc. I AEC, Metropolitan Museum, Nova York - Inv. 26.60.3 $3^{12}$

\section{Culto imperial de Augusto}

Os romanos durante muito tempo não cultuaram os vivos. Sua religião e seu panteão os bastavam. O comum era ter em conta e guardar para gerações futuras figuras proeminentes

\footnotetext{
${ }^{8}$ Ver Martins (2011b, p. 104-11); (2013a, p. 18-122); (2013b, p. 221-37) e Martins; Amato (2012, p. 125-58).

${ }_{9}^{9}$ Prop. 2.3.41-42.

${ }^{10}$ Martins; Amato (2012, p. 134-39; p. 149-53).

${ }^{11}$ C IAC - Imagens da Antiguidade Clássica - http:/ /iac.fflch.usp.br/imagines - Foto: Paulo Martins, visualizado 23 de nov. de 2020 .

${ }^{12}$ C IAC - Imagens da Antiguidade Clássica - http:/ /iac.fflch.usp.br/imagines - Foto: Paulo Martins, visualizado 23 de nov. de 2020.
} 
da sociedade romana por meio de honras que lhe eram conferidas pela república, a exemplo de coroas, escudos, estátuas ainda que essas sempre estivessem na esfera privada a serviço da honra aos ancestrais, em acordo com ius imaginum, de sorte que a elite não reconhecia nenhum ser humano como superior e, portanto, o senado não concedia a cidadão algum tal estatuto de superioridade. Assim, se alguém fosse considerado oficialmente divino, isto era inequivocamente contra os costumes (mores) republicanos. Mesmo que aquelas honras concedidas aos romanos de valor pudessem ser convenientes aos deuses inclusive, ninguém, vivo ou morto, devia ser considerado divino. ${ }^{13}$

O mos maiorum, por seu turno, era justamente o conjunto de valores que ditava as honras concedidas pela república e nele se balizavam os cidadãos insignes. Diante desse quadro, como podemos entender circunstancialmente o culto imperial de Augusto? Creio que alguns aspectos devem ser conjugados a fim de que o processo de divinização passe a ser considerado possível pelos romanos, a saber, a estirpe, o triunfo, os dii familiares, as imagines, além da instrumentalização do senado que pari passu foi afrouxando os mores republicanos no sentido de ampliar as auctoritates de Otávio Augusto no último quartel do I século AEC.

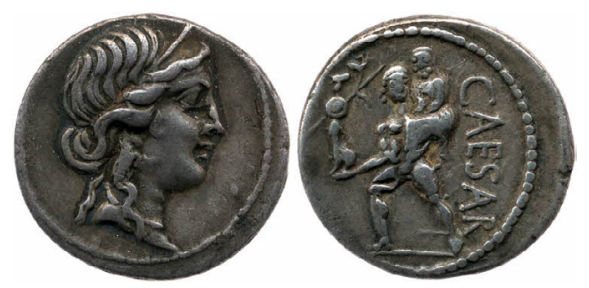

Figura 3 - RRC $458^{14}$ - Denário de Prata, África, 47-46 AEC, The British Museum, Londres

Como pode ser observado no primeiro denário da época de Júlio César (figura 3), embora não se admitisse o culto aos vivos, fica claro que a mensagem já está sendo veiculada, já que se tem no obverso Vênus como que protegendo o reverso no qual observa-se Eneias, carregando Anquises com a chancela de César, por que entre a Deusa, o filho da deusa e o pai do filho da deusa pairaria a rubrica de Caesar, a não ser pelo fato de ele, Júlio César, ser uma espécie de aposto resumitivo das três entidades míticas apresentadas na moeda. Nesse sentido, Otávio Augusto se filia a essa linhagem. Antes dessa moeda ser cunhada, Otávio já era filho adotivo de Júlio César (43 AEC) de modo que por contiguidade metonímica ele já teria sua estirpe divina registrada. O que é comprovado pelo denário seguinte (figura 4), no qual no obverso Otávio assume a posição que era de Vênus na moeda anterior (figura 3), já no reverso têm-se a deusa com um elmo, uma lança e um escudo, ilustrado com uma estrela de oito pontas, onde há a inscrição Caesar Divi [Filius] - César filho do divino -

\footnotetext{
${ }^{13}$ Ver Martins (2013a, p. 230-49); (2014a, p. 81-94).

${ }^{14}$ (C) The Trustees of British Museum. Ver Ghey, E. (ed.); Leins, I. (ed.); Crawford, M. H. (2010). A catalogue of the Roman Republican Coins in the British Museum, with descriptions and chronology based on M.H. Crawford, Roman Republican Coinage (1974). 458.1.11. Ver RRC 458/1 (type). Acessado em: 23 de nov. de 2020.
} 
assim a deusa além de apresentar-se como numa óbvia alusão à estirpe de Otávio, ela está paramentada com armas numa estreita relação com as guerras civis, principalmente com as vitórias da gens Iulia.

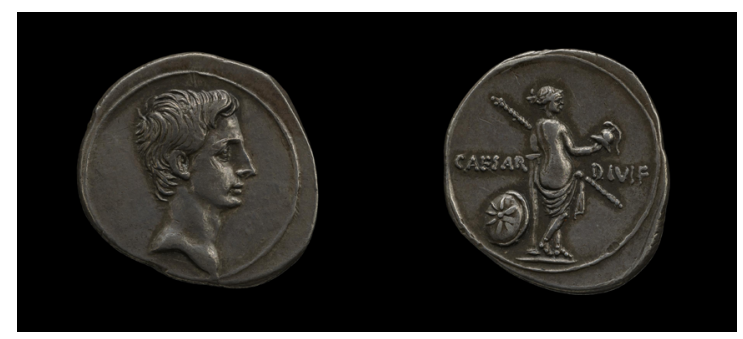

Figura 4 - RIC I 250A - Denário de Prata, Brundisium e Roma, 32-29 AEC, The British Museum, Londres ${ }^{15}$

A segunda relação divina, assumida por Otávio Augusto, é com Apolo, principalmente, depois de Ácio. A fundação de Nicópolis, onde havia um templo a Apolo, e a própria construção do templo de Apolo Palatino, próximo de sua casa são ações significativas. Não podem ser esquecidas as duas estátuas que nos restaram em que se observa a figuração de um Augusto/Apolo. ${ }^{16}$ A moeda seguinte apresenta tanto a associação de Augusto com Apolo como a indicação hereditária de filiação divina, já que no obverso observam-se a efígie de Augusto e a inscrição AVGVSTVS DIVI F[ilius] e no reverso um Apolo citarista, segurando um lira com a inscrição IMP[perator] X e ACT[tium] - Imperador por dez vezes e Ácio. Vale observar que, apesar de ser cunhada entre 15-13 AEC, a moeda ainda mantém a referência a Ácio, não só pela inscrição ACT como também pela figuração de Apolo Citarista.
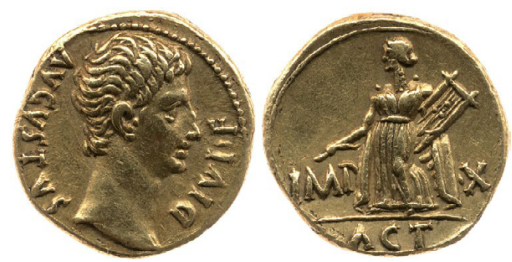

Figura 5 - RIC I 170 - Aureus, Lugdunum, 15-13 AEC, The British Museum, Londres ${ }^{17}$

Mary Beard em suas considerações sobre o culto imperial relativizou a importância de uma arqueologia desse culto tendo em vista o culto ministrado a certos monarcas no mundo helenístico. ${ }^{18}$ Acredito, entretanto, que algumas considerações sejam essenciais para

\footnotetext{
15 (c) The Trustees of British Museum. Acessado 24 de nov. de 2020.

${ }^{16}$ Ver https://commons.wikimedia.org/wiki/File:Auguste-arles1.jpg acessado em 23/11/2022 e https://www.livius.org/pictures/greece/thessaloniki/thessaloniki-museum-pieces/thessalonikistatue-of-augustus/, acessado em 23/11/2020.

17 C The Trustees of British Museum. Acessado 24 de nov. de 2020. Ver RIC I 170; Lyon 27; Calicó 215; BMCRE 459-60 = BMCRR Gaul 173-4; BN 1394-5. Ver também Martins (2013, p, 271) e Martins (2017b, p. 461-8). Ver também BMC 461, RIC I 180, RIC I 192

${ }^{18}$ Beard (2007, p. 233).
} 
a compreensão do padrão figurativo das estátuas a partir de Augusto, mesmo porque é inegável a relação a ser observada entre Augusto e Alexandre e não é passível de refutação a proximidade do culto ao $\alpha \gamma \alpha \theta$ o $\delta \alpha i ́ \mu \omega v$ no mundo grego e ao genius no mundo latino.

Pelo que se tem notícia, desde muito tempo os gregos cultuavam os seus mortos, mas não da mesma maneira com que celebravam os olímpicos, de sorte que, aos fundadores de cidades e aos heróis, cumpriam-se homenagens, sacrifícios e honras específicas. Efetivamente, aos heróis, as famílias gregas davam suas honras custeadas "perpetuamente" pelas $\pi$ ó $\lambda \varepsilon ı \zeta$. Com semelhantes honras, os fundadores de cidades eram cultuados, entretanto ainda em

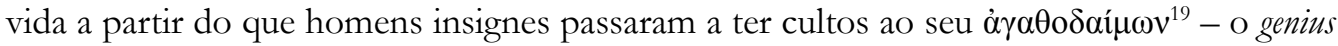
romano, como explicita o LSJ. ${ }^{20}$ As homenagens ao $\alpha \gamma \alpha \theta o \delta \alpha i ́ \mu \omega v$ se imiscuíram ao culto de

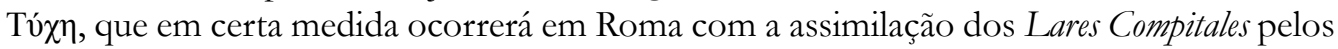
Augustales e sua relação com o culto a Mercúrio. ${ }^{21}$

Alexandre, por seu turno, já fora o primeiro governante helenístico a tornar a divinização prática comum entre os gregos. No seu caso específico, o fato de ter sido considerado faraó pelos egípcios acresceu ao fato de os macedônicos acreditarem na hereditariedade da divindade da família real. Já os ptolomeus e os selêucidas limitavam sua divindade ao período de sua vida. Ocorre, entretanto, que nem foram todas as dinastias gregas que se consideram divinas, tampouco permaneceram a cultuar o filho de Filipe II da Macedônia. Mas devo lembrar que é inequívoca a apropriação da imago de Alexandre (figura 6) por Augusto em vários aspectos. O próprio retrato do tipo B - do qual nos restaram 18 exemplos - é uma citação, segundo Galinsky, dos retratos de Alexandre de Lisipo. ${ }^{22}$

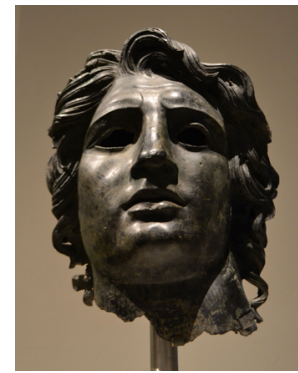

Figura 6 - Bronze de Alexandre, o grande, a partir de Lisipo, c. 150 AEC - 138 EC - Metropolitan Museum, Nova York - Inv. L 2012.4.124

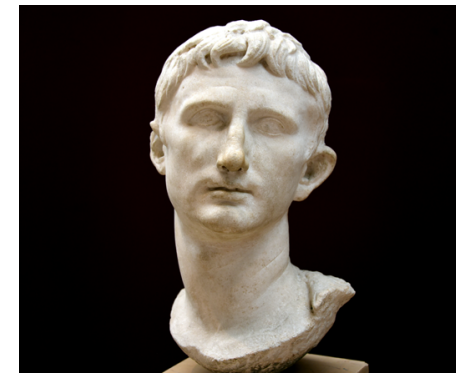

Figura 7 - Cabeça de Augusto de Bergama - Museum of Archaeology, Istambul ${ }^{23}$

${ }^{19}$ Taylor $(1975$, p. 8-9).

${ }^{20}$ LSJ (1977, p. 4).

${ }^{21}$ Martins (2017a, passim).

${ }^{22}$ Ver Galinsky (1996, p. 166-67).

${ }^{23}$ CC BY-SA 4.0 https://en.wikipedia.org/wiki/Cultural_depictions_of_Augustus\#/media/ File:Head_of_Augustus_from_Bergama,_in_modern-day_Turkey._Museum_of_Archaeology,_ Istanbul.jpg., acessado 23 de nov. de 2020.

${ }^{24}$ C IAC - Imagens da Antiguidade Clássica - http:/ /iac.fflch.usp.br/imagines - Foto: Paulo Martins, visualizado 23 de nov. de 2020. 
No fim da república, observa-se um afrouxamento dessa resistência ao culto em alguns episódios envolvendo Sula, Mário, Pompeu e Júlio César. Tanto o primeiro como o segundo fundaram cidades e deram-lhes seus próprios nomes. Sula possuía jogos em sua honra e Mário tinha um culto não oficial em seu nome. Pompeu, por seu turno, foi autorizado a usar seus ornamenta triumphalia por ocasião dos jogos no Circus Maximus. ${ }^{25} \mathrm{O}$ primeiro e terceiro sustentam sua relação especial com Vênus. Mário, por sua vez, acreditava na sua imortalidade já que, para ele, nenhum homem seria capaz de matá-lo. Ocorre, porém, que apenas Júlio César veio a se tornar deus ainda que após a sua morte. Sua apoteose está associada ao cometa que surgiu no mesmo dia que foi decretada sua deificação pelo Senado. Vale dizer que sua divinização não exclui aspectos semelhantes ao dos três anteriores associados a ele em vida.

Mas, definitivamente, quando a leste de Roma os gregos passam a realizar cultos e construir templos aos seus governadores romanos, isso passa a ser digno de regulações do Senado. Sob Augusto, Dio Cássio ${ }^{26}$ informa que os romanos do oriente desde cedo passaram a prestar culto a Roma e a Júlio divinizado. E foi permitido aos nativos dessa região construir lugares sagrados e a prestar culto a Augusto. O historiador também indica que o culto do imperador vivo difere entre os habitantes de Roma e os do oriente, afinal esses já estavam habituados a deificar seus governantes desde Alexandre, enquanto aqueles não. Contrariamente ao que propõe Dio Cássio ${ }^{27}$ quanto à recusa do culto de Augusto em vida por ele mesmo, Taylor apresenta vasta epigrafia que comprova que inúmeras municipalidades antes de 14 EC já se dedicavam ao seu culto e já lhe erigiam templos.

Em 29 AEC por um senatus consultum o gênio de Augusto passa a dividir com o gênio do pater familias os lararia das domus. Fato que determina dois pontos importantes: sua representação pública passa a ser exposta privadamente e sua imagem adquire por contiguidade a ideia de paternidade. Entre as cidades itálicas a adotar a prática, temos Pompeia, Nápoles, Cumas, Benevento, Terracina, Praeneste, Pisa, Perúgia, Verona, Pula e Aquileia. Já há em 2 EC autorização do Senado a Augusto em Nápoles. ${ }^{28}$ Em 7 o genius Augusti passa a receber culto nos Lares compitales, cuja abrangência em Roma são os 165 cruzamentos da urbs, vazando da domus à rua.

Enfim, Garsey e Saller sintetizam que o culto imperial foi estabelecido em bases helenísticas e romanas. A primeira nos cultos dos monarcas helenísticos, a segunda promovida por Roma em honra de Augusto durante sua vida e depois dela. Ambas vertentes se difundiram rapidamente pelo império, adaptando-se a especificidades itálicas, de um lado, e a características provinciais, de outro, tanto quanto à sua recepção como quanto à sua expressão. $^{29}$

\footnotetext{
${ }^{25}$ Taylor (1975, p. 57). Ver Cic., Att. 1.18.6; Ver Vell. 2.40.4.

${ }^{26} \mathrm{DC}, 51.20$.

${ }^{27}$ DC, $51.20-21$.

${ }^{28}$ Taylor (1920, p. 116-33). A epígrafe de Tácito neste trabalho trata justamente de supostas recusationes ao culto imperial de Tibério à semelhança de Augusto.

${ }^{29}$ Garsey; Saller (2015, p. 187-205).
} 
Quando se diz que a figuração pública de Augusto passa a ocupar lugar no âmbito privado isso corresponde à replicação de sua imagem monumental, seja como Pontifex Maximus (figura 8), seja como Genius (figura 9), ambas, acabam por subverter o espaço da imagem republicana das casas nobres nas quais os columbaria eram responsáveis por guardar as imagines maiorum em outra base figurativa.

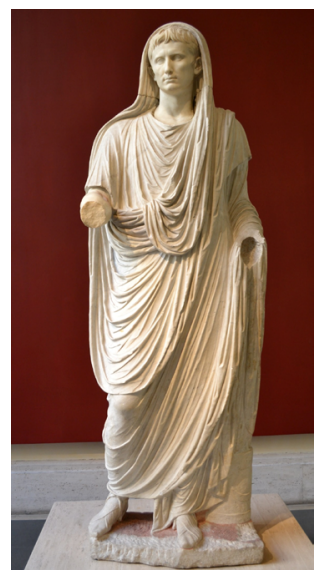

Figura 8 - Augusto da Via Labicana como Pontifex Maximus - MNR - Palazzo Massimo alle Terme, Roma - Inv.: 56230, altura: $2.05 \mathrm{~m}^{31}$

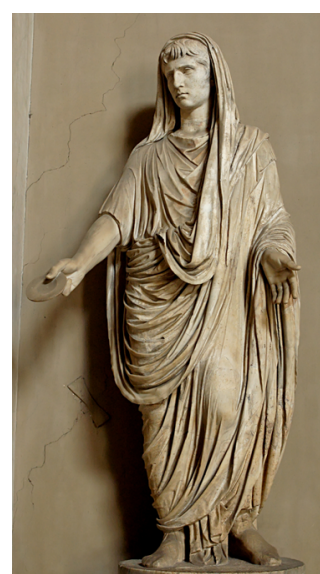

Figura 9 - Gênio de Augusto do Museu Pio Clementino, Vaticano - Inv.: 259 ${ }^{30}$

Além da redução do tamanho da estátua monumental pública, a fim de que se acomodasse aos lararia e se coadunasse com as estatuetas do pater familias (figuras 10 e 11), o que significaria uma redução de 200 centímetros para 12-20 centímetros, outros tipos de estatuetas de Augusto assomam-se a essas: pequeninos bustos ou retratos (figuras 12 e 13) em novo estilo que passam a povoar esses altares domésticos ao lado dos Lares dançantes, Penates e Gênios. Deve-se lembrar que, segundo Plínio, o velho, passam a proliferar na domus da elite, nas bibliotecas as estátuas de pensadores cujo estilo remete ao simulacrum, afinal não há notícias de qual fosse, por exemplo, a fisionomia de Homero. Esse tipo de imagem, portanto, se coaduna também ao novo estilo. ${ }^{32}$

\footnotetext{
${ }^{30} \odot$ IAC - Imagens da Antiguidade Clássica - http:/ /iac.fflch.usp.br/imagines - Foto: Paulo Martins, visualizado 23 de nov. de 2020 .

31 ○ IAC - Imagens da Antiguidade Clássica - http:/ /iac.fflch.usp.br/imagines - Foto: Paulo Martins, visualizado 23 de nov. de 2020.

${ }^{32}$ Plin. Nat. 35.1-7.
} 


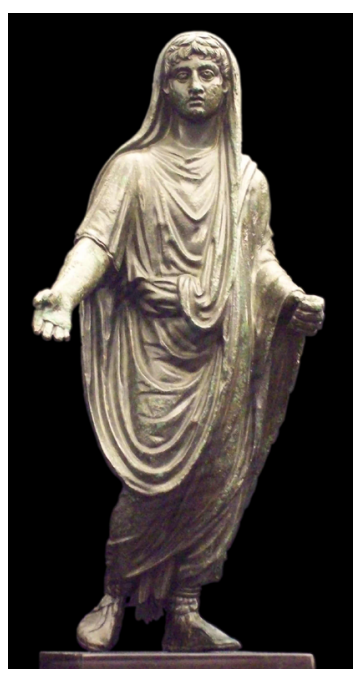

Figura 10 - Gênio como Pater Familias de Ponte Puñide - Museu Arqueológico Nacional, Madri - M.A.N. 1928-60-133

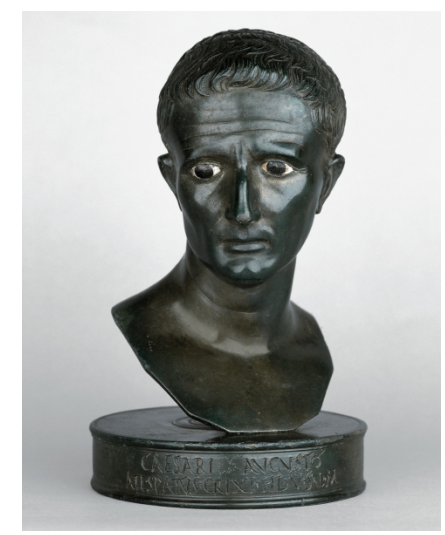

Figura 12 - Augusto de Neuilly-le-RéalMuseu do Louvre, Paris - Inv.: Br $28^{35}$

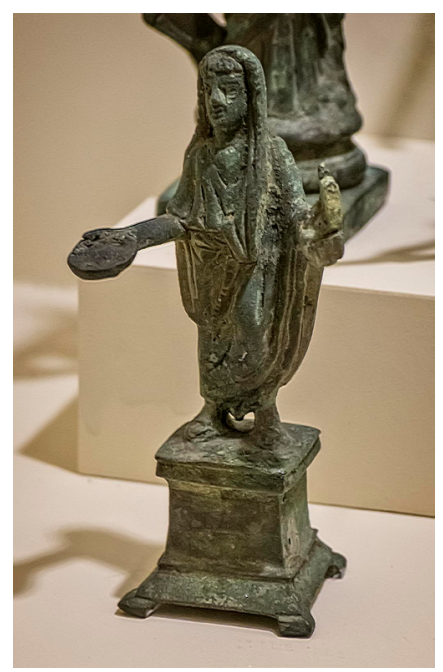

Figura 11 - Pater Familias da Villa Boscoreale - The Walters Art Museum, Baltimore $^{34}$

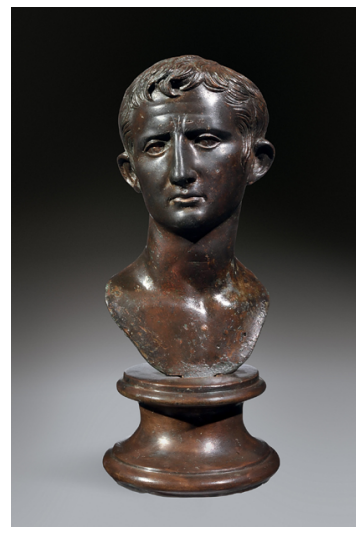

Figura 13 - Augusto de Nápoles MANN, Nápoles - Inv:: $5473-19.6 \mathrm{~cm}$

\footnotetext{
${ }^{33}$ @ C Museu Arqueológico Nacional, Madri. https://pt.wikipedia.org/wiki/Ficheiro:Genio_romano_ de_Ponte_Pu\%C3\%B1ide_(M.A.N._1928-60-1)_01.jpg, acessado em 28/06/2019. Foto: Luis García. CC BY-SA 3.0

34 @ The Walters Galery. https://www.flickr.com/photos/mharrsch/24127878546/in/photostream/, acessado em 16/09/2018. Foto: Mary Harrsch. CC BY-NC-SA 2.0

35 (CC BY-AS 2.0) (C) Carole Redatto https://www.flickr.com/photos/carolemage/14464649857 Acessado em 8/5/2019.
} 


\section{A PERENIDADE DO MONUMENTO: MEMÓRIA CULTURAL}

A relação entre monumentalidade e perenidade não é evidente, portanto carece de ser explicitada. O que acabamos de observar é que o culto imperial concorreu para a mudança do padrão de figuração de Augusto. Isso sem excluirmos obviamente as associações da gens Iulia e Vênus, tampouco a ligação de Otávio a Apolo e a Mercúrio entre 30 AEC e 2 EC, ou mesmo, post mortem a Júpiter.

Tal alteração, podemos precisamente dizer, levou o retrato do modo effigies ao do simulacrum e imprimiu nesse matiz de retrato fortes traços de vigor físico, ou, como Turcan enfatiza, certo ímpeto de confiança e sentimento de segurança que a persona do princeps inspira. Na verdade, este novo retrato, engendrado e consolidado pelo culto imperial, é a expressão de uma política, se não um meio de governo, ou a representação de um regime. Assim, este novo retrato deixa de ser a afirmação de uma fisionomia que repercute o mos maiorum e, portanto, reflexo de valores pessoais, familiares e gentílicos. A difusão da nova imago multiplica e descentraliza os efeitos, já que publiciza para além da domus e da urbs a mensagem da nova ordem que se instaura. ${ }^{36}$ Todas essas informações contidas nessa mensagem apontam para a sua condição monumental ou perene. O retrato de Augusto torna-se passível de rememoração contínua transistoricamente, que opera contor" nos divinos já observados no retrato helenístico a partir de Alexandre, e que dirige o olhar dos espectadores para a figura sempre nova, afastando-se da similaridade exclusiva ao modelo tal e qual - a effigies republicana. Sua imagem, assim, associada ao rito religioso presente nos altares nos vici e nas domi, romanas e provinciais, consolida-se de forma que, anos depois sob Adriano, verifica-se a circulação de imagens de Augusto. Observe-se esta passagem de Suetônio:

Thurinum cognominatum satis certa probatione tradiderim nactus puerilem imagunculam eius aeream ueterem ferreis et paene iam exolescentibus litteris hoc nomine inscriptam, quae dono a me principi data inter cubicu $<$ li $>$ Lares colitur. ${ }^{37}$

Irei apresentar por prova suficientemente cabal ter nascido com sobrenome Turino, eu mesmo ter obtido uma antiga estatueta de bronze, dele menino (Augusto), cuja inscrição de ferro e quase já apagada tinha este nome inscrito. Essa estatueta dei ao príncipe (Adriano) que a cultua no cubículo entre os seus Lares.

Uma curiosa estatueta pode ser facilmente associada a esta questão:

\footnotetext{
${ }^{36}$ Turcan (1995, p. 83-86).

${ }^{37}$ Suet., Aug., 7.
} 


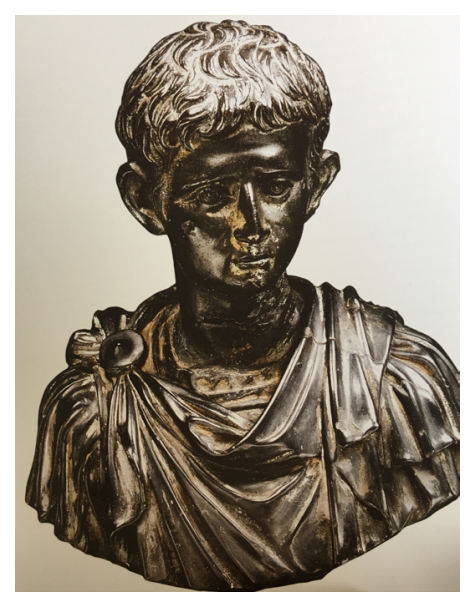

Figura 14 - Museu Arqueológico de Florença -

Estatueta de Augusto $(14 \mathrm{~cm})$ - I séc. EC

Seja como for, ainda que os ritos e cultos venham a ser sempre um despertar da memória coletiva e cultural, parece-me que os instrumentos evocativos dessa memória ou são atos escritos ou são obras de escultura e de arquitetura. Esses elementos de cultura material ou intelectual são os responsáveis pela evocação do passado e a perpetuação da recordação, pois são monumentos. ${ }^{38}$

Em meu trabalho de 2011, associo a temática da "representação divina" dos simulacra de Augusto a uma preocupação atemporal da imagem, isto é, como devem ser lidos em chave futura e não coetânea, já que se fixa como perene. ${ }^{39}$ Sua função, portanto, é a preservação da memória coletiva. Entretanto diferentemente da história que pode se apresentar como "memória universal do gênero humano", a memória, embora coletiva em nosso caso como representação de uma única pessoa, Augusto, como bem esclarece Halbwachs, não é universal, pois que "a pour support un groupe limité dans l'espace et dans le temps". ${ }^{40}$

Qualquer alteração nessas condicionantes, isto é, no tempo e no espaço, significa indispô-la, memória, com sua própria natureza, pois estaríamos a subverter o passado atribuindo-lhe sentidos não previstos naquele tempo e naquele espaço por aquele grupo, e dessa forma uma memória coletiva revisitada por outro grupo deixa de lado sua natureza e passa a representar o grupo que a reutilizou; a memória coletiva, portanto, se nega a refletir o passado, fora de seu ambiente, de sorte que, se reutilizada, passa a ser presente representativo para a cultura que lhe assimilou, ainda que possa estar nela ecoado longinquamente algum valor simbólico de um passado que não lhe pertence.

\footnotetext{
${ }^{38}$ Le Goff (1996, p. 535-53).

${ }^{39}$ Ver Martins (2011, p. 197-206).

${ }^{40}$ Halbwachs (1968, p. 75).
} 
Daí as imagens têm sua função específica na história do principado de Augusto. Ocorre, porém, que, ao se replicar a mesma operação imagética de "perenização" tendo como objeto, por exemplo, Tibério ou Cláudio, estamos a reproduzir o sistema de figuração e não a imagem de Augusto. Por outro lado, ainda que tenhamos a imagem de Augusto tomada post mortem, fora de seu tempo - a não ser que pessoas desse futuro ou desse lugar tenham dele participado -, não estamos mais a revivê-lo em sua presença ou em sua "realidade", mas a recolocá-lo "dans les cadres, dans lesquels l'histoire dispose les événements, cadres qui restent exterieurs aux groupes les uns aux autres." ${ }^{41}$

\section{Poesia Como monumento: ReCENS LAUDE}

Da mesma maneira que a arte do simulacrum foi operada no sentido de construir perenização de Augusto ou para denotar sua imortalidade divina, em outro nível e com outros objetivos, a poesia augustana revigora a formulação da perenidade, associada ao novo. Vale lembrar que essa é tópica poética que remonta à lírica arcaica grega, revistada no período helenístico. É-me claro que na épica também se verifica o mesmo lugar-comum, contudo trabalhado em contexto heroico. Acredito que a ideia de que qualidade da arte reside na sua capacidade de sobrestar ao artífice é fundamental para entender esse lugar-comum, que

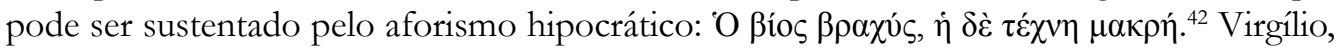
na Eneida em discurso direto de Júpiter diz a respeito dos heróis: "Stat sua cuique dies, breue et irreparabile tempus/omnibus est uitae; sed famam extendere factis/ hoc nirtutis opus - a cada um seu dia está decretado, é breve e irreparável o tempo/de vida a todos; mas concede fama aos feitos/ esta obra da virtude". ${ }^{43}$ Assim a ideia da imortalidade, associada à imagem divina, ao poeta e ao herói, garante a circulação da mensagem de sua imagem. Obviamente o fato de o poeta morrer e sua poesia permanecer viva não é algo senão a própria perenidade do poeta no exercício de sua arte. Assim se a arte do simulacro pereniza o figurado, o cinzelador ou o escultor pode também ser reconhecido como imortal a depender do resultado de sua arte. A poesia lírica também o faz ao evidenciar a valorização do sujeito da enunciação poética que, muita vez, se confunde com a figura do poeta, personalizadamente. Na épica augustana, no canto 6 da Eneida, numa véкvı, o poeta sintetiza a ideia de imortalidade, propondo simultaneamente o passado, o presente e o futuro a fim de plasmar a alma imorredoura nessa atemporalidade. Entendo que o poeta nessa obra está se propondo como o herói que busca, assim como outros poetas do período ser imortal, ao lado do princeps. Há de se lembrar que, na Divina Comédia, Virgílio acompanha Dante de forma a retraduzir a metáfora de Eneias.

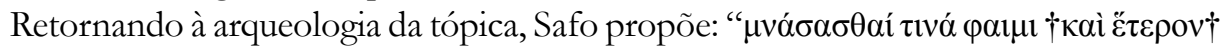
$\grave{\alpha} \mu \mu \varepsilon ́ \omega v$ - alguém, eu digo, há de lembrar de mim no futuro", ${ }^{44}$ se sua vida não é imortal,

\footnotetext{
${ }^{41}$ Halbwachs (1968, p. 75).

${ }^{42}$ Hipp., Aph.1.1.

${ }^{43}$ Verg., A.10.468.

${ }^{44}$ Sapph. 147 LP
} 
sua habilidade poética o é. Calímaco, num epigrama, falando de seu amigo poeta, Heráclito, diz: "Alguém me contou, Heráclito, de sua morte, caí em lágrimas (...) hoje em algum lugar de Halicarnasso você não é mais do que velha cinza, mas teus rouxinóis, eles sim vivem. O Hades, que tudo arrasa, jamais irá se apoderar deles." 45

Acchar, precisamente, ainda que com escopo diverso, diz "poetas como Píndaro assimilariam seu mister ao de artesãos: de fato, eles comparam seus cantos a esculturas, monumentos, mármores, a obras tecidas, tramadas, costuradas..." . "Embora essas questões, ao que parece, sobrevivam pelo menos desde Homero, afinal fazia parte de sua ação, como poeta, compor seu canto de modo que pudesse sobreviver mnemonicamente, e só isso já o associa ao monumentum, parece-me - mediado por Catulo ${ }^{47}$ possivelmente - que o século de Augusto, com todas as implicações político-religiosas, reposiciona o lugar comum da imortalidade da obra em estreita relação com o princeps e com o nouum. Essa relação significa associar o princeps senatus e o princeps poetarum, na medida que ambos agenciam o "angeo", ou melhor, o escultor pereniza o figurado em sua escultura, o poeta pereniza o objeto de sua poesia e o governante na arte de governar pereniza sua cidade. Todos os objetos da imitação nesses casos operam a elevação que permite associá-los a homens superiores aristotelicamente.

Tanto Horácio no último poema do terceiro livro de Odes (Carm., 3.30) como Ovídio, nos versos finais de As metamorfoses (Met.15.871-879), irão se valer da relação à qual me referi ao observar a arte do simulacro. Vejamos:

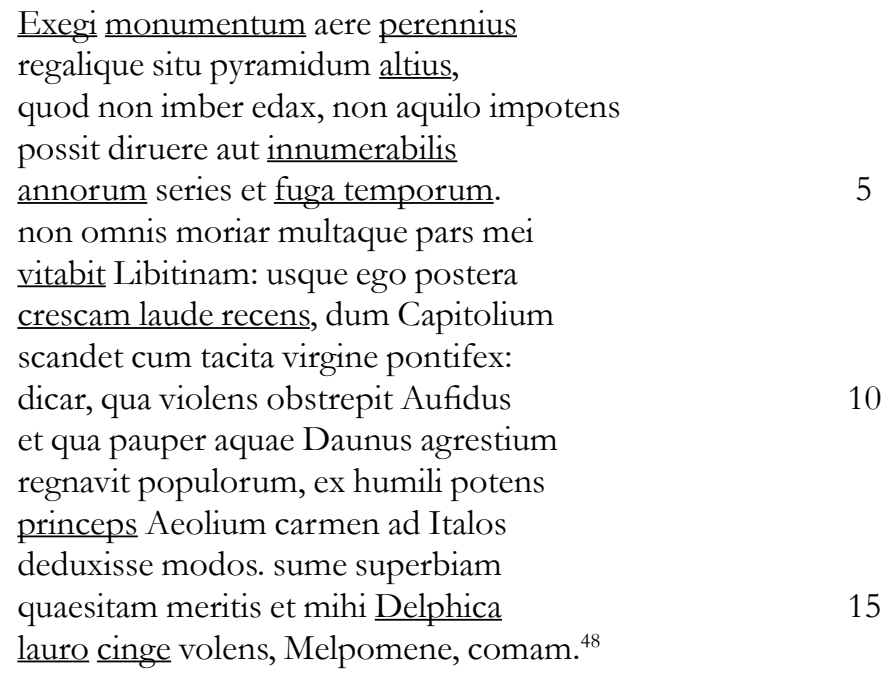

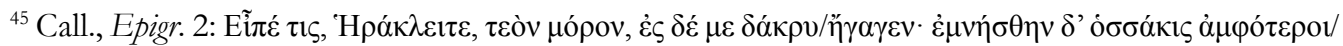

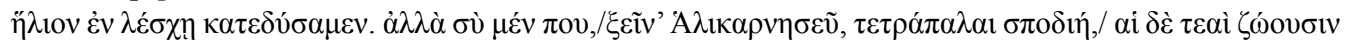

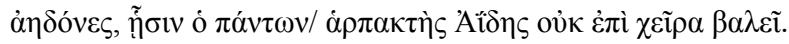

${ }^{46}$ Acchar (1994, p. 159).

${ }^{47}$ Catull. 1. 8-10: "quare habe tibi quidquid hoc libelli,/qualecumque quidem, patroni ut ergo/ plus uno maneat perenne saeclo."

${ }^{48}$ Hor., Carm. 3.30.
} 
Erigi um monumento mais perene que o bronze, mais alto que a real velhice das pirâmides, para que nem a chuva devastadora, nem o Aquilo colérico possam destruir, nem a inumerável série de anos, nem a fuga dos tempos.

Não morrerei de todo e a mor parte de mim Irá sobreviver à Libitina: eu sempre e em todo lugar irei renascer novo pelo louvor, enquanto com a virgem calada o pontífice escalar o Capitólio:

Serei considerado onde o Áufido violento encrespa, e onde o pobre Dauno reinou sobre os povos agrestes: de origem simples, sou o primeiro capaz de ter trazido aos itálicos modos o poema eólico. Toma grandeza desejada pelos méritos, Melpômene, e se desejar, cinge minha cabeça com o louro de Delfos.

Iamque opus exegi, quod nec Iovis ira nec ignis nec poterit ferrum nec edax abolere vetustas. cum volet, illa dies, quae nil nisi corporis huius ius habet, incerti spatium mihi finiat aevi:

parte tamen meliore mei super alta perennis astra ferar, nomenque erit indelebile nostrum, quaque patet domitis Romana potentia terris, ore legar populi, perque omnia saecula fama, siquid habent veri vatum praesagia, vivam. ${ }^{49}$

E já erigi a obra, para que nem a ira ou fogo de Jove, nem ferro, nem tempo voraz possam abolir. Quando ele quiser, o dia, que só tem direito sobre este corpo, me imponha o fim de incerta vida: contudo, na minha melhor parte, seja levado perene além dos altos astros e meu nome será indelével, e onde a potência romana estiver presente em terras dominadas, serei elevado pela boca do povo e por todos os séculos pela fama e se algo de verdadeiro há nos presságios dos poetas irei viver.

Tanto o primeiro poema como o segundo inserem-se na representação do simulacrum naquilo que o associa ao monumentum, ao opus, àquilo que é duradouro, aere perenius ou alta perennis astra. Assim essa nova poesia, a poesia augustana, assim como a própria cidade, que passa a ser de mármore e o princeps que passa a ser divino contextualmente estão a serviço da pax de Augusto, da urbs aeterna, na mesma chave que o simulacrum ou "o classicismo augustano"

${ }^{49}$ Ov., Met. 15.871-879. 
opera a arte plástica. Na verdade, corroborando a hipótese, Tibulo é o primeiro a propor a perenidade da própria Roma: "Romulus aeternae nondum firmauerat urbis moenia - Rômulo ainda não havia firmado os muros da cidade eterna". ${ }^{50}$

É interessante observar que tanto Horácio como Ovídio falam da sua obra a elevando à perenidade, de sorte que ainda que retirem de si, seres mortais, a vida, quando se tem como base uma sinédoque de obra pelo autor conferem a esse, personalizadamente, condição superior já que sobrevive depois da morte. Assim "a inumerável série de anos" ou "a fuga dos tempos", de um lado, e o eu "seja louvado perene além dos altos astros e meu nome seja indelével" igualam o poeta a Augusto, daí ser interessante notar a adoção do verbo exigo no perfeito, isto é, exegi, termo diretamente associado à arquitetura e à ideia de princeps no verso de Horácio “ex humilipotens princeps” cujo destino é ser coroado com o louro de Delfos, logo, ao louro de Apolo da mesma maneira que Augusto. Por fim, infiro que Horácio ou a emulação de Ovídio ampliam a imagem de Augusto, não só quando o colocam no cerne do epíditico como é comum, mas também quando conferem a ele por metonímia a própria função poética, isto é, Augusto também sobrevive como poeta.

\section{REFERÊNCIAS}

ACCHAR, F. Lirica e lugar-comum. São Paulo: Edusp, 1994.

BEARD, M. The Roman triumph. Cambridge, Mass \& London: The Belknap Press of Harvard University Press, 2007.

GALINSKY, K. Augustan Culture. Princeton: Princeton University Press, 1996.

HALBWACHS, M. La mémoire collective. Préface de Jean Duvignaud. Paris: Presses Universitaires de France, 1968.

MARTINS, P. Augusto como Mercúrio enfim. Revista de História, v. 176, p. 1-43, 2017a. DOI: https://doi.org/10.11606/issn.2316-9141.rh.2017.116333

MARTINS, P. Texto e imagem: História. Como se faz a História sob(re) Otávio/Augusto. In: SILVA, Glaydson J.; SILVA, M. A. O. (org.). A ideia de História na Antiguidade Clássica. São Paulo: Alameda \& FAPESP, 2017b, p. 437-468.

MARTINS, P. Tum longas condimus Iliadas: a Helena de Propércio, Archai, v. 21, 2017c. DOI: https://doi.org/10.14195/1984-249X_21_5

MARTINS, P. Os romanos, o direito, a imagem e a morte. In: FAVERSANI, F.; JOLY, F. As formas do império romano. Ouro Preto: EDUFOP, 2014a, p. 81-94.

MARTINS, P. Vertentes do Retrato Romano no final da República e no início do Principado. Cad. Pesq. Cdhis, Uberlândia, v. 27 n. 2, p. 13-38, jul./dez. 2014b.

DOI: https://doi.org/10.14393/cdhis.v27i2.32618

\footnotetext{
${ }^{50}$ Tib. 2.5.21. Ver Ov., Fast. 3.72 e Liv. 4.4 e 28.28.
} 
MARTINS, P. Pictura loquens, poesis tacens. Limites da representação. Tese (Livre-docência) Departamento de Letras Clássicas e Vernáculas, Universidade de São Paulo, 2013a.

MARTINS, P. Constructing Cicero. Nuntius Antiquus, v. 9, n. 2, p. 221-237, 2013b. DOI: https://dx.doi.org/10.17851/1983-3636.9.2.221-237

MARTINS, P. Imagem e Poder. Considerações sobre as representações de Otávio Augusto. São Paulo: EDUSP, 2011.

MARTINS, P. Vt Pictura Rhetorica. Revista USP, 91, p. 104-11, 2011. Dor: https://doi. org/10.11606/issn.2316-9036.v0i91p104-111

MARTINS, P.; AMATO, R. S. S. Imagens antigas retoricamente referenciadas. In: MUHANA, A.; LAUDANNA, M.; BAGOLIN, L.A. (org.). Retórica. São Paulo: IEB-USP \& Annablume, 2012, p. 125-58.

NISBET, R. G. M.; HUBBARD, M. A Commentary on Horace Odes: Book 1. Oxford: Clarendon Press, 1970.

POLLITT, J. J. The Art of Rome c. 753B.C. - A.D. 337. Sources and Documents. Cambridge: Cambridge University Press, 1998.

RAMAGE, N.H.; RAMAGE, A. Roman art. New Jersey: Pearson, 1991.

RUIZ, M. P. El culto en la casa romana. In: Anales de Prehistoria y Arqueologia, v. 23-24, p. 199229, 2008.

SALLES, C. L'Antiquité romaine. Paris: Larousse, 1993.

SHAYA, J. The public life of monuments: The Summi Viri of the Forum of Augustus. American Journal of Archaeology, v. 117, n. 1, p. 83-110, 2013.

DOI: https://doi.org/10.3764/aja.117.1.0083

STEWART, P. Statues in Roman society. Representation and response. Oxford: Oxford University Press, 2003.

TAYLOR, L. R. The divinity of the Roman emperor. American Philological Association, 1931; repr. Arno Press, 1975.

TRIMBLE, J. Corpore enormi. The rethoric of physical appearance in Suetonius and Imperial portrait statuary. In: ELSNER, J.; MEYER, M. Art and rethoric in Roman culture. Cambridge: Cambridge University Press, 2014, p. 115-154.

DOI: https://doi.org/10.1017/CBO9780511732317.006

TURCAN, R. L'Art Romain. Paris: Flamarion, 1995.

WALKER, S. Roman Art. British Museum. Cambridge, Mass.: Harvard University Press, 1991.

ZANKER, P. The power of the images in the Age of Augustus. Ann Harbor: The University of Michigan Press, 1990. 